\title{
Okul öncesi bütünleştirme uygulamalarında özel gereksinimli ve tipik gelişen çocukların sosyal kabulleri: Boylamsal bir çalışma*
}

\author{
Social acceptence of children with and without special needs in inclusive \\ preschools: A longitidunal study
}

\author{
Hatice Bakkaloğlu ${ }^{1}$, Ahmet Bilal Özbek ${ }^{2}$, N. Bülbin Sucuoğlu ${ }^{3}$
}

\begin{abstract}
Makale Geçmişi
Geliş : 18 Mart 2020

Düzeltme : 9 Mayis 2020

Kabul : 10 Mayis 2020
\end{abstract}

\section{Makale Türü}

Araştırma Makalesi

\section{Article History}

Received : 18 March 2020

Revised : 9 May 2020

Accepted : 10 May 2020

Article Type

Research Article
Öz: Bu çalışmanın amacı, okul öncesinde bütünleştirme ortamlarındaki özel gereksinimli (ÖG) ve tipik gelişen (TG) çocukların sosyal kabul düzeylerini boylamsal olarak incelemektir. Bu amaçla çalışmanın verileri Sosyometrik Dereceleme Ölçeği ile Güz ve Bahar döneminde olmak üzere iki kez toplanmıştır. Çalışma grubunda 12 bağımsız anaokulundaki 41 sınıfa devam eden 47 ÖG ve 47 TG çocuk yer almıştır. ÖG ve TG çocukların Güz ve Bahar dönemi değerlendirme sonuçları karşılaştırılmış; bulgular TG çocukların sosyal kabul düzeylerinin hem Güz hem de Bahar döneminde, ÖG çocuklardan daha yüksek olduğunu göstermiştir. Ayrıca ÖG ve TG çocukların Güz ve Bahar dönemi ölçümleri arasında grup içinde farklılaşma olmadığı; her iki grubun Güz-Bahar dönemi ölçümleri arasındaki farklar karşılaştırıldığında ise iki grubun ölçümler arasındaki farkların da anlamlı düzeyde farklılaşmadığı belirlenmiştir. Bulgular alanyazın ışığında tartışılmıştır.

Anahtar Kelimeler: Özel Gereksinimli Çocuk, Tipik Gelişen Çocuk, Bütünleştirme, Okul Öncesi, Sosyal Kabul

Abstract: The aim of this study is longitudinally investigating social acceptance levels of children with and without special needs (SN) in inclusive preschools. Data were collected with the Sociometric Rating Scale on fall and spring data points of one school year. Participants of the study were 47 children with $\mathrm{SN}$ and 47 children without SN from 41 classrooms and their teachers from 12 different preschools. Results indicated that social acceptance of children with $\mathrm{SN}$ was significantly lower than their typically developing peers on both fall and spring measurements. It was also found that the social acceptance scores of both groups of children did not change significantly from the fall to spring measurements. Findings were discussed in terms of related research literature.

Keywords: Children with Special Needs, Typically Developing Children, Inclusion, Preschool, Social Acceptance

*Bu çalışma, Türkiye Bilimsel ve Teknolojik Araştırma Kurumu'nca (TÜBİTAK) desteklenen “Okul Öncesinde Kaynaştırma Eğitimine Devam Eden Özel Gereksinimli Olan ve Olmayan Çocukların Gelişimlerinin Boylamsal Analizi” adlı projeden [114K649] üretilmiştir.

Başlica Yazar: Hatice BAKKALOĞLU, Ankara Üniversitesi Eğitim Bilimleri Fakültesi, Özel Eğitim Bölümü, Cebeci ANKARA

${ }^{1}$ Ankara Üniversitesi, Eğitim Bilimleri Fakültesi, Özel Eğitim Bölümü, hbakkaloglu@ankara.edu.tr, ORCID: orcid.org/0000-0002-3226-9077

${ }^{2}$ Dokuz Eylül Üniversitesi, Buca Eğitim Fakültesi, Özel Eğitim Bölümü, bilal.ozbek@deu.edu.tr, ORCID: orcid.org/0000-0002-0200-4932

${ }^{3}$ Hacettepe Üniversitesi, Eğitim Fakültesi, İlköğretim Bölümü, bulbinsucuoglu@hacettepe.edu.tr, ORCID: orcid.org/0000-0002-8733-9765 


\section{SUMMARY}

\section{Introduction}

Inclusion is seen as an effective way to reduce prejudice, discrimination, negative attitudes and it aims to create a socially inclusive society (Booth \& Ainscow, 2013). The fact that typically developing (TD) peers' presenting models for cognitive and social skills to children with special needs (SN) in inclusive classrooms is lacking in segregated classrooms (Guralnick, 2001). Inclusive practices aim to support children with SN much more effectively and it is expected to create awareness for individual differences in early childhood for TD children. Quality of interactions between children with SN and their TD peers and their teachers carries great importance for the success of the early childhood inclusion (Odom et al., 2004). When children with SN participate in activities with their peers and during learning opportunities provided during those activities, TD peers provide a model to them (Justice, Petscher, Schatschneider, \& Mashburn, 2011).

Inclusion practices are believed to be beneficial for the integration and acceptance of children with SN into society. In our country, children with SN mostly start their education life in preschools within the scope of inclusion. Although different dimensions of inclusive education in preschools and primary schools have been examined (Aguiar, Moiteioro, \& Pimentel, 2010; Baydık \& Bakkaloğlu, 2009; Ferreira, Aguiar, Correia, Fialho, \& Pimentel, 2017), it has not yet been examined whether attending inclusive preschools causes changes in the social acceptance of children with and without SN. Social acceptance of children with SN by their TD peers is an important variable both for achieving the positive effects expected from inclusion and supporting the development of children with SN. Because of this, it is seen that there is a need for new research studies to examine the social acceptance of children with and without SN to determine the effects of inclusive education and to improve the quality of inclusion. It is thought that results from those studies will show the pathways to create much more effective inclusive schools. The research questions of this study are listed below.

1. Is there a significant difference between fall and spring social acceptence levels of children with and without SN?

2. Is there a significant difference between fall and spring social acceptence levels within the groups of children with and without SN?

3. Is there a significant difference between fall and spring social acceptence changes of children with and without SN?

\section{Method}

This study was planned according to the longitudinal research design. Longitudinal research design is a type of research that allows creating causal relationships and making reliable inferences by observing changes over time (Cohen, Manion, \& Morrison, 2007). A total of 94 children (47 children with SN and 47 with TD) 
from 41 classrooms in 12 different preschools which are affiliated with the Ministry of National Education and with a separate building in Ankara participated in the study.

Demographic Information Form was developed by the researchers to determine the demographical characteristics of the children and teachers in the study group. This form was filled out by teachers. Data collection process took place in the fall and spring semesters of the 2015-2016 educational year in OctoberNovember and April-May. The Sociometric Rating Scale was used by one of the project members and was applied one on one with children. The Sociometric Rating Scale is a reliable tool for measuring social acceptance (Asher, Singleton, Tinsley \& Hymel, 1979).

\section{Results}

When the scores obtained from fall and spring measurements were compared between the two groups, it is seen that there was a significant difference. When the social acceptance scores of the children obtained from the fall and spring measurements were examined, it was determined that children without SN got higher scores than children with SN.

When fall and spring social acceptance levels of children with SN were compared it was seen that there was no significant difference, but when the mean scores obtained in the measurements were examined, a small decrease in the social acceptance levels in the spring measurements was seen. When the fall-spring measurement scores of children without SN were compared with the Wilcoxon Signed Ranks Test, it was seen that there was no significant difference in the social acceptance levels. It is determined that there was a small decrease in the social acceptance levels of children without $\mathrm{SN}$ in the spring measurements.

When the changes between the social acceptance levels in the fall-spring measurements of the children with and without $\mathrm{SN}$ were examined, there was no significant difference between the two groups. There was no significant difference between the changes in the social acceptance levels of both groups from fall to spring.

\section{Conclusion and Discussion}

In this research social acceptance levels of children with and without $\mathrm{SN}$ were longitudinally examined between and within groups. Results showed that children without SN had higher social acceptance levels than their peers with SN on both fall and spring semesters. These findings are consistent with the results of the similar studies in the literature (Bakkaloğlu, Sucuoğlu, \& Özbek, 2019; Buysse, Goldman, \& Skinner, 2002; Ferreira et. al., 2017; Keane \& Calkins, 2004; Koster, Pijl, Nakken, \& Van Houten-van den Bosch, 2010; Mand, 2007; van der Wilt, van der Veen, van Kruistum, \& van Oers 2019).

Higher social acceptance of children with SN and creating awareness for individual differences of children without $\mathrm{SN}$ were two important expected outcomes of inclusive classrooms. However findings showed that social acceptance levels of children with SN awere low and remained as it is at the end of the school year. 
Why social acceptance levels didn't increase? Social acceptance is defined as attitudes toward an individual. Attitudes are judicial ideas and it may take time for them to change. Children with SN may show problem behaviors, communication and social skills problems and these factors decrease their social acceptance (de Boer, Pijl, Post, \& Minnaert, 2013). Previous research has shown that children with SN show higher problem behavior levels than their TD peers in preschools (Bakkaloğlu et. al., 2019; Keane \& Calkins, 2004). These are the possible explanations of findings. 


\section{GİRIŞ}

Bütünleştirme önyargıy1, ayrımcıllğı ve olumsuz tutumları azaltmanın en etkili yolu olarak görülmekte; sosyal kabulü yüksek bir toplum oluşturmayı hedeflemektedir (Booth ve Ainscow, 2013). Özel eğitim sınıfları ile karşılaştıııldığında, bütünleştirme ortamlarında tipik gelişen (TG) akranlar özel gereksinimli (ÖG) çocuklara bilişsel ve sosyal beceriler için uygun modeller sunmaktadırlar (Guralnick, 2001). Böylece ÖG çocukların gelişimlerinin daha etkin bir şekilde desteklenmesi hedeflenirken aynı zamanda TG çocukların da erken dönemden itibaren bireysel farklılıklara ilişkin farkındalıklarının oluşması beklenmektedir. Bütünleştirme uygulamalarına katılan ÖG çocukların okul öncesi eğitimden en iyi şekilde yararlanabilmeleri için yetişkinlerle ve akranlarıyla nitelikli etkileşimler kurmaları önemlidir (Odom ve diğerleri, 2004). ÖG çocuklar akranları ile birlikte etkinliklere katıldıklarında ve etkinlikler sırasında kendilerine çeşitli öğrenme fırsatları sağlandığında, TG çocuklar ÖG akranlarının öğrenmelerine model olabilmektedir (Justice, Petscher, Schatschneider ve Mashburn, 2011).

Sosyal kabul, grup üyelerinin bireylere yönelik duygularının (beğenme, beğenmeme) toplu değerlerini yansıtan bir tutum olarak tanımlanabilir (Buhs ve Ladd, 2001). Akranlar tarafindan kabul edilme çocukların etkinliklere katılmaları ve akranları ile etkileşime girerek öğrenme fırsatlarından daha fazla yararlanmaları açısından önemli bir değişkendir. Erken dönemde çocukların akranları tarafından kabul edilmeleri, ileri yaşlardaki akademik başarıları, okula devamlanı, zayıf benlik algısı ve duygusal-davranışsal sorunları ile ilişkilidir (Kingery, Erdley ve Marshall, 2011; Lewis ve Doorlag, 1999; Parker ve Asher, 1987; Prinstein ve Giletta, 2016). Akranları tarafindan reddedilen çocuklar etkinliklerde kendilerine daha az yer bulabilmekte ve akranları bu çocuklarla etkileşime girmekten kaçınmaktadırlar (Ladd, Kochenderfer ve Coleman, 1996). ÖG çocukların akranları tarafından kabul görmesi, erken çocukluk döneminde sosyal etkileşimlerini arttırarak sosyal yeterliliğe ulaşmalarını desteklerken, akranlar tarafindan reddedilme ve sosyal kabulün düşük olması ise bu çocukların bütünleştirme uygulamalarından yararlanmalarını güçleştirmektedir (Odom ve diğerleri, 2006).

Sosyal kabul birbiriyle ilişkili pek çok değişkenden etkilenmektedir. Örneğin okul öncesi dönemde ortak/benzer oyunlar oynama, etkileşim firsatları, benzer bilgi ve ilgilere sahip olma gibi faktörler çocukların birbirleriyle etkileşimini etkileyebilmektedir (Dietrich, 2005). Diğer taraftan, çocukların bireysel farkl11ıkları da sosyal kabullerini etkileyen önemli bir faktör olarak kabul edilmektedir (Diamond, Hong ve Tu, 2008; van der Wilt, van der Veen, van Kruistum ve van Oers, 2019). Örneğin ÖG çocukların yetersizliklerinin türü ve derecesi (Ferreira, Aguiar, Correia, Fialho ve Pimentel, 2017), öğretmenleri ile ilişkileri (Rudasill, Niehaus, Buhs ve White, 2013), problem 
davranışları (Keane ve Calkins, 2004; Mand, 2007) ve sosyal becerileri (Cambra ve Silvestre, 2003; Denham ve Holt, 1993) ile okula uyum düzeyleri (Buhs, Ladd ve Herald, 2006) sosyal kabulleri üzerinde etkili değişkenlerdir.

Sosyal beceriler ve problem davranışlar, birbirleriyle ilişkili olan (Arnold, Kupersmidt, Voegler-Lee ve Marshall, 2012) ve okul öncesi dönemde çocukların sosyal kabulleri ile ilerideki akademik başarılarını etkileyen önemli değişkenlerdir (Montroy, Bowles, Skibbe ve Foster, 2014; Stone ve diğerleri, 2013; Vaughn, Elbaum ve Schumm, 1996). Diğer taraftan problem davranışlar ve sosyal becerilerin öğretmen-çocuk ilişkisi ve okula uyumları ile de ilişkili olduğunu gösteren çalısmalar bulunmaktadır (Demirkaya ve Bakkaloğlu, 2015; Jerome, Hamre ve Pianta, 2009; Reed-Victor, 2004; Roorda, Verschueren, Van Craeyveldt, Van Craeyveldt ve Colpin, 2014). Okul öncesi kurumlarda çocukların problem davranışları akranları tarafindan olumsuz bir şekilde etiketlenmelerine sebep olmakta ve edinilen bu izlenimlerin değişmesi kolay olmamaktadır (Johnson, Ironsmith, Snow ve Poteat, 2000). Bu davranışlar çocukların akranları ve öğretmenleri ile olan ilişkilerini olumsuz etkilemekte ve reddedilmelerine yol açabilmektedir (Keane ve Calkins, 2004). Diğer taraftan çocukların sosyal becerileri, problem davranışları ve mizaçları ile de ilişkili olabileceği belirlenen öğretmen-öğrenci ilişkisinin niteliği (Demirkaya ve Bakkaloğlu, 2015; Rudasill, 2011; Rudasill, Niehaus, Buhs ve White, 2013; Silver, Measelle, Armstrong ve Essex, 2005), çocukların hem eğitim ortamından yararlarını hem de ileri okul yaşantılarını etkilemektedir (Ewing ve Taylor, 2009; Hamre ve Pianta, 2001). Ancak bütünleştirme uygulamalarının başarıya ulaşmasında rolü çok fazla olan öğretmenlerin ÖG çocuklarla ilişkileri TG çocuk-öğretmen ilişkisine göre daha azdır (Bakkaloğlu, Sucuoğlu ve Özbek, 2019; Demirkaya ve Bakkaloğlu, 2015; Prino, Pasta, Gastaldi ve Longobardi, 2016). Öğretmen ile olumsuz ilişkiler ise çocuğun sınıfa uyumu etkilemekte (Birch ve Ladd, 1997) ve hem okuldan uzaklaşma (Palermo, Hanish, Martin, Fabes ve Reiser, 2007) hem de düşük akademik becerilere (Hamre ve Pianta, 2001) yol açmaktadır. Oysa okula uyum çocukların okul kuralları ve rutinlerine uyum sağlamalarını, okula yönelik olumlu tutum sahibi olmalarını, grupla ve bireysel olarak sınıf etkinliklerine katılmalarını ve öğretmen ve akranları ile olumlu ilişkiler geliştirmelerini içeren bir değişkendir (Herndon, Bailey, Shewark, Denham ve Bassett, 2013). Okul öncesi eğitim ortamları düşünüldüğünde çocukların öğretmenlerinin yönergelerini dinlemeleri, sabahları kendilerine ait olan dolaplarına giderek çantalarını bırakmaları, günaydın çemberine katılmaları ve kahvaltı için sıraya girmeleri okulun kurallarına ve rutinlerine uyum sağladıklarını gösterir. Çocuğun grup ile uyum içerisinde hareket etmesi akranları ve öğretmeni ile olan ilişkilerini etkilemekte (Ladd, Birch ve Buhs, 1999); ancak ÖG olan çocukların okula uyumları NG akranlarına göre düşük olabilmektedir (Bakkaloğlu ve Sucuoğlu, 2018). Küçük çocukların sosyal becerileri ve sosyal problem çözme becerileri 
(Nakamichi, Nakamichi ve Nakazawaile, 2019) ile öğretmen ve akranlarla olumlu ilişkileri (Ladd, Kochenderfer ve Coleman, 1997) okula uyumlarını kolaylaştırırken; akran reddi ile problem davranışları hem uyumlarını olumsuz etkilemekte hem de sınıf etkinliklerine katılmalarını güçleştirmektedir.

Aguiar, Moiteioro ve Pimentel (2010) bütünleştirme uygulamaları yürütülen 68 okul öncesi sınıfı inceledikleri çalışmalarında ÖG çocukların TG akranlarına göre zayıf sosyal kabule sahip olduklarını ve çocukların sosyal kabullerini yordayan en güçlü değişkenlerin çocukların yaş ve yetersizlikten etkilenme düzeyleri olduğunu belirlemişlerdir. Bir diğer çalışmada bütünleştirme kapsamında okul öncesi eğitimlerine devam eden 86 ÖG çocuğun sosyal kabul, sosyal beceri ve problem davranış düzeyleri incelenmiştir (Ferreira ve diğerleri, 2017). Araştırmacılar sosyal becerileri zayıf olan çocukların düşük sosyal kabul düzeyleri gösterdiklerini ve problem davranışları yüksek olan çocukların reddedilme riski ile karşı karşıya olduklarını ifade etmişlerdir. Bir başka çalışmada $\mathrm{Yu}$, Ostrosky ve Fowler (2015) okul öncesindeki TG çocukların yetersizliği olan akranlarına yönelik tutumlarının birlikte oynama ve etkileşimleri ile ilişkisini incelemişler ve TG çocukların yetersizliği olduğunu bildikleri akranları ile daha az etkileşime girdiklerini ve sosyal kabul düzeyi arttıkça birlikte oynanan oyunlarının arttığını ifade etmişlerdir. Ülkemizde yapılan bir çalısmada (Bakkaloğlu ve diğerleri, 2019) ise, ÖG çocukların TG akranlarına göre sosyal kabul, öğrenci-öğretmen ilişkisi, sosyal beceri ve okula uyum puanlarının daha düşük, problem davranışlarının ise daha yüksek olduğu bulunmuş ve tüm çocukların sosyal kabulünü yordayan en güçlü değisskenin problem davranışlar olduğu belirlenmiştir.

ÖG çocukların sosyal kabul düzeylerinin incelendiği araştırmalar içerisinde boylamsal çalışmaların sayısının oldukça sınırlı olduğu görülmektedir. 2. ve 3. sınıflara devam eden ÖG öğrencilerin TG akranları ile karşılaştırıldıkları bir araştırma, öğrencilerin öğretim yılının başında ve sonunda yapılan değerlendirmelerde akranlarından daha zayıf sosyal kabul düzeyleri gösterdiklerini ve öğrenme güçlüğü tanısı olan çocukların TG çocuklarla arkadaşlıklarının sayısının yıl sonunda azaldığını göstermiştir (Tur-Kaspa, Margalit ve Most, 1999). Katılımcılar arasında ÖG çocukların yer almadığ1 bir boylamsal çalışmada ise anaokulunda zayıf sosyal kabulü olan çocukların birinci ve ikinci sınıfta da akranları tarafindan dışlandıkları görülmüştür (O’Neil, Welsh, Parke, Wang ve Strand, 1997). Okul öncesi dönemde ise ÖG çocukların sosyal kabul düzeylerinin boylamsal olarak incelendiği çalışmaya rastlanmamıştır.

Bütünleştirme uygulamalarının özel gereksinimli çocukların topluma entegrasyonu ve kabulleri için yararlı olacağına inanılmaktadır. Ülkemizde de ÖG çocuklar bütünleştirme uygulamaları 
kapsamında okul öncesi eğitim kurumlarında eğitim hayatlarına başlamaktadırlar. Okul öncesi ve ilkokul düzeyinde yürütülen bütünleştirme uygulamaları farklı boyutlarda incelenmesine karşın (Aguiar ve diğerleri, 2010; Baydık ve Bakkaloğlu, 2009; Ferreira ve diğerleri, 2017), okul öncesi kurumlara devam etmenin ÖG ve TG çocukların sosyal kabullerinde değişmeye yol açıp açmadığı araştırılmamıştır. Oysa ÖG çocukların TG akranları tarafindan kabul edilmeleri, hem bütünleştirmeden beklenen olumlu etkinin sağlanabilmesi hem de ÖG çocukların gelişimlerinin desteklenmesi için önemli bir değişkendir. Bu nedenle bütünleştirme uygulamalarının etkisinin belirlenmesi ve bütünleştirme uygulamalarının niteliğinin artırılması amacıyla gerekli düzenlemelerin yapılabilmesi için ÖG ve TG çocukların sosyal kabul düzeylerinin yıl içinde gösterdikleri değişimlerin inceleneceği çalışmalara ihtiyaç olduğu görülmektedir. Bu çalışmaların sonuçları, okul öncesi kurumların, özellikle ÖG çocuklar başta olmak üzere tüm çocukların sosyal kabullerini ne kadar etkilediğini gösterecek ve iyileştirme çalışmaları için alınması gereken önlemlere 1şık tutacağı düşünülmektedir. Bu çalışmada aşağıdaki araştırma sorularına yanıt aranmıştır.

1. ÖG ve TG çocuk gruplarının, Güz ve Bahar ölçümlerine göre sosyal kabulleri arasında anlamlı fark var midir?

2. ÖG ve TG çocuk grupları içinde Güz-Bahar ölçümlerine göre sosyal kabulleri arasında anlamlı fark var midır?

3. ÖG ve TG çocuk grupları arasında Güz-Bahar ölçümlerindeki değişimlere göre sosyal kabul düzeyleri arasında anlamlı fark var mıdır?

\section{YÖNTEM}

\section{Çalışma Deseni}

Bu çalışma boylamsal araştırma desenine göre planlanmıştır. Boylamsal araştırma deseni zaman içerisindeki değişim gözlenerek nedensel ilişkiler kurulmasına ve güvenilir çıkarımlar yapılmasına imkân sağlayan bir araştırma türüdür (Cohen, Manion ve Morrison, 2007). Bu araştırmada okul öncesi dönemde ÖG ve TG çocukların sosyal kabul düzeyleri açısından bir öğretim yılının başında (Güz) ve sonundaki (Bahar) durumlarını ve bu iki gruptaki çocukların iki ölçümde gösterdikleri değişimleri karşılaştırmak amacıyla boylamsal araştırma deseni kullanılmıştır.

\section{Çalışma Grubu}

Çalışma grubu geniş kapsamlı bir çalışma olan TÜBİTAK 1001 destekli bir projenin katılımcılarının bir kısmından oluşmaktadır. Çalışmaya Ankara ilindeki 12 bağımsız anaokulundaki 41 okul öncesi 
sınıfa devam eden 47 ÖG ve 47 TG çocuk katılmıştır. Çalışmada yer alan okul öncesi sınıfların öğretmenlerinin tümü üniversite mezunudur ve yaş ortalamaları 30,86 yıl (ranj=23-46 y1l), çalışma deneyimi süreleri ortalaması ise 7,65 yıldır (ranj=1-20 yll). Veri toplanan 41 sinıfin 35'inde bir, 6’sında ise iki ÖG çocuk bulunmaktadır. Her sınıftaki ÖG çocuklar çalışma grubuna dahil edilmiştir. Bu çocuklar hastanelerin ilgili birimlerince tanı konulan ve Rehberlik Araştırma Merkezleri tarafından bütünleştirme uygulamaları kapsamında okul öncesi sınıflara yerleştirilen çocuklardır. Çalışmaya katılan ÖG çocukların 9’u fiziksel yetersizlik ve/veya sağlık problemleri, 14'ü zihinsel yetersizlik, 10'u dil ve konuşma bozukluğu, 12'si otizm spektrum bozukluğu ve 2'si işitme yetersizliği tanısına sahiptir. Sınıflardaki ÖG çocuklar belirlendikten sonra öğretmenden ÖG çocukla aynı cinsiyette ve benzer sosyoekonomik düzeyde olan, ancak gelişimsel bir problemi bulunmayan bir çocuğu seçmesi istenmiş ve bu çocuklar da TG çocuk olarak araştırmada yer almışlardır. Öğretmenler, çocuk gelişimi konusundaki bilgileri ve birçok çocuğu gözleme firsatına sahip olmaları nedeniyle çocukların yeterliliklerini ve yetersizliklerini objektif olarak belirlemede önemli ve güvenilir kaynaklardır (McDermott, 1993). Bu nedenle alanyazında (Demir, 2016; Bakkaloğlu ve Sucuoğlu, 2018) sınıflarındaki TG çocukların belirlenmesi amacıyla sıklıkla öğretmenlerin görüsslerine başvurulduğu görülmektedir. Çalışma grubunda yer alan çocuklar 4 ve 5 yaş grubu sınıflarına devam etmektedirler. Veri toplama süreci başlangıcında 4 yaş grubu katılımcılarının okul öncesi eğitim devam süresi 2 ay iken, 5 yaş grubu için okula devam süresi 14 aydir.

Çalışma grubu belirlendikten sonra gruplar arasında demografik özellikler açısından fark olup olmadığını incelemek amacıyla ÖG ve TG çocuklar yaş ve cinsiyetleri açısından karşılaştırılmıştır. İki grup arasında yaş $(\mathrm{t}=.409, \mathrm{p}=.683)$ ve cinsiyet dağıllımı $\left(X^{2}=.049, \mathrm{p}=.825\right)$ bakımından anlamlı farklılık bulunmadığı belirlenmiştir. Çalışmaya katılan ÖG ve TG çocukların demografik özellikleri Tablo 1'de verilmiştir.

Tablo 1. ÖG ve TG çocukların demografik özellikleri

\begin{tabular}{lcccccccccc}
\hline Çalışma & \multicolumn{9}{c}{ Yaş (Ay) } & \multicolumn{7}{c}{ Cinsiyet } & \multirow{2}{*}{ Toplam } \\
\cline { 2 - 11 } Grubu* & $\mathbf{X}$ & SS & Ranj & $\mathbf{t}$ & $\mathbf{p}$ & $\mathbf{K 1 z}$ & Erkek & $X^{2}$ & p & 47 \\
\hline ÖG & 54.67 & 4.12 & $49-68$ & \multirow{2}{*}{409} & .683 & 17 & 30 & \multirow{2}{*}{.049} & .825 & 47 \\
TG & 54.33 & 3.77 & $48-61$ & & & 17 & 30 & & & 94 \\
\hline Toplam & 54.50 & 3.93 & $48-68$ & & & 34 & 60 & & \\
\hline
\end{tabular}

*ÖG: Özel Gereksinimli, TG: Tipik Gelişen

\section{Veri Toplama Araçları}

\section{Demografik bilgi formu}


Çalışma grubunda yer alan çocukların ve öğretmenlerinin demografik bilgilerini belirlemek için araştırmacılar tarafindan Demografik Bilgi Formu geliştirilmiştir. Bu form öğretmenler tarafindan doldurulmuştur.

\section{Sosyometrik dereceleme ölçeği (SDÖ)}

Çalışma grubunda yer alan çocukların sosyal kabul düzeyleri sosyometrik tekniklerden akran derecelendirme yöntemi ile değerlendirilmiştir. Akran derecelendirme yöntemi okul öncesi dönemde akran tercihi gibi diğer sosyometrik yöntemlere göre daha güvenilir kabul edilmektedir (Asher, Singleton, Tinsley ve Hymel, 1979; Balda, Punia ve Punia, 2002; Kapcı ve Çorbac1-Oruç, 2003). Bu yöntemde bir sınıftaki her çocuğun, her bir akranı hakkındaki görüşü ayrı ayrı belirlenmektedir (Asher ve diğerleri, 1979). Akran derecelendirme yöntemi ile çocukların sosyal kabul düzeylerini tespit etmek için sınıf listeleri kullanılarak her sınıf için ayrı SDÖ formu hazırlanmıştır. Bağımsız bir uygulamacı her bir çocukla bireysel olarak çalışarak verileri toplamışır (ayrıntılar için bkz. Verilerin Toplanması ve Analizi). SDÖ’nün güvenirliği, test-tekrar test yöntemi ile incelenmiş; değerlendirme yapılan sınıflardan seçkisiz olarak belirlenen 5 sınıfta 2-3 hafta arayla iki ölçüm yapılmış; iki ölçümden elde edilen puanlar arasında anlamlı düzeyde olumlu ilişki (r=.350; $\mathrm{p}<.01$ ) olduğu görülmüştür. SDÖ'nün geçerliğini incelemek amacıyla çalışmada yer alan çocukların sınıf öğretmenlerinden (Andrade ve diğerleri, 2005; Baydık ve Bakkaloğlu, 2009) çocukların sosyal kabul düzeylerini akranları gibi üçlü derecelendirme ile puanlamaları istenmiştir. Öğretmenlerin çocuklara verdikleri sosyometrik derecelendirme puanları ile çocukların akranlarından aldıkları sosyometrik derecelendirme puanları arasındaki ilişki incelendiğinde, öğretmenler ile akran değerlendirmeleri arasında anlamlı düzeyde olumlu ilişki ( $\mathrm{r}=.568 ; \mathrm{p}<.01)$ olduğu görülmüştür. $\mathrm{Bu}$ sonuçların SDÖ ile yapılan sosyal kabul ölçümlerinin güvenilir ve geçerli olduğunu gösterdiği kabul edilmiştir.

\section{Verilerin Toplanması ve Analizi}

Bu çalışma daha geniş kapsamlı bir TÜBİTAK 1001 projesinde elde edilen verilerin bir bölümünden oluşmaktadır. Proje kapsamında çalışılan çocukların aileleri de projede yer almışlardır. Milli Eğitim Bakanlığından alınan veri toplama izninin yanı sıra aileler ve öğretmenlerden aydınlatılmış onam formları ile izin alınmıştır. Veri toplama sürecinde öncelikle Milli Eğitim Bakanlığı alınan araştırma izni ile bağımsız anaokullarına başvurularak çalışmaya katılacak okullar ve sınıflar belirlenmiştir. Araştırmanın verileri 2015-2016 öğretim yılının Güz döneminde EkimKasım ayları ve Bahar döneminde Nisan-Mayıs aylarında toplanmıştır. Çalışma grubunun sosyal kabulleri araştırma ekibinden bir uygulamacı tarafindan SDÖ ile her çocukla bireysel olarak 
çalışılarak değerlendirilmiştir. Bu amaçla ilk olarak sınıf listeleri kullanılarak her bir sınıf için bir matris oluşturulmuştur. Bu matrisin dikey ve yatay sütunlarında sınıftaki çocukların adlarına yer verilerek matris küçük kutucuklara bölünmüş, böylece her çocuğun her bir akranına ilişkin yaptığ1 derecelendirmelerin kaydedileceği kutucuklar oluşturulmuştur. Sınıf matrislerin hazırlanmasının ardından öğretmenlerden sınıftaki tüm çocukların vesikalık fotoğrafları istenmiş ve arkalarına çocukların isimleri yazılarak uygulama için hazır hale getirilmiştir. Diğer taraftan sosyometrik derecelendirmede çocukların tercihlerini göstermeleri için akranlarının fotoğraflarını içine atacakları, her birinin üzerinde mutlu, nötr ve üzgün yüz ifadeleri yer alan üç kutu hazırlanmıştır. Ardından sınıftaki her çocuk sınıf listesindeki sıra ile birer birer çağrılarak sınıfın uzak köşesinde bir masada çalışılmıştır. Çocuklara birlikte oyun oynanacağı söylenmiş, oyunun kuralları açıklanmış ve yanıtlarının uygulamacı ile çocuk arasında sır olarak kalacağı belirtilerek çocuğa başka sorusu olup olmadığ1 sorulmuştur. Daha sonra değerlendirici önce çocuğa bir fotoğraf göstermiş, fotoğraftaki arkadaşının kim olduğunu sormuştur. Çocuk doğru yanıtı verdikten sonra fotoğraftaki arkadaşı ile birlikte oyun oynamaktan hoşlanıyorsa fotoğrafi, üzerinde gülen yüz bulunan kutuya, hoşlanmiyorsa üzgün yüz bulunan kutuya, emin değilse, kararsızsa ya da bilmiyorsa nötr yüz bulunan kutuya atmasını istemiştir. Çocuklar ile çalışılırken etik ilkeler açısından "sevme-sevmeme" gibi ifadelerin kullanılmamasına özen gösterilmiştir. Son olarak her çocuğun akranları için yaptığı derecelendirmeler (oyun oynamaktan hoşlanma 3, emin olmama 2 ve hoşlanmama 1 puan) matrise işlenmiştir. Sınıftaki tüm arkadaşları için derecelendirmeleri tamamlanan çocuğa teşekkür edilerek arkadaşlarının yanına gidebileceği söylenmiştir. Ortalama 20-22 çocuk bulunan sınıflarda uygulamanın tamamlaması 30-35 dakika sürmüştür. Tüm çocuklar için uygulama tamamlandıktan sonra her çocuğun akranlarından aldığı puanlar toplanmış ve derecelendirme yapan akran sayısına bölünerek o çocuk için sosyometrik derecelendirme puanı hesaplanmıştır (Baydık ve Bakkaloğlu, 2009; Frederickson ve Furnham, 1998; Odom ve diğerleri, 2006).

Veri toplama süreci tamamlandıktan sonra veriler SPSS programı kullanılarak analiz edilmiştir. Öncelikle betimsel analizler ve normallik testleri yapılmıştır. Çalışma grubunda yer alan ÖG ve TG çocukların ölçümler arasında göstermiş oldukları değişimin karşılaştırılması amacıyla Bahar ölçüm puanlarından Güz ölçüm puanları çıkarılarak fark puanları elde edilmiştir. Her iki grubun Güz ve Bahar ölçümleri için normallik testleri yapıldığında verilerin normal dağılım göstermediği belirlenmiştir. Kolmogorov-Smirnov normallik testi sonuçları Tablo 2'de verilmiştir. Veriler normal dağıllım göstermediği için ÖG ve TG çocukların Güz ve Bahar ölçümlerine göre kendi grupları içindeki sosyal kabul düzeylerinin karşılaştırılması amacıyla Wilcoxon İşaretli Sıralar testi, ÖG ve TG çocukların Güz ve Bahar ölçümlerinin karşılaştırılması ve her bir grubun Bahar-Güz 
ölçümlerindeki değişim düzeylerinin karşılaştırılması amacıyla ise Mann Whitney-U testi kullanılmıştır.

\section{BULGULAR}

$\mathrm{Bu}$ bölümde çalışmadan elde edilen verilerin araştırma soruları kapsamında analiz edilmesi sonucunda ulaşılan sonuçlara yer verilmiştir. Öncelikle araştırmada elde edilen verilerin betimsel istatistikleri ve normallik analizi sonuçları Tablo 2'de sunulmuştur. Daha sonra araştırma soruları çerçevesinde çalışmanın bulguları verilmiştir.

Tablo 2. Betimsel istatistikler ve normallik analizi sonuçları

\begin{tabular}{|c|c|c|c|c|c|c|c|c|c|c|c|c|}
\hline \multirow{3}{*}{ Ölçek* } & \multicolumn{6}{|c|}{ ÖG** } & \multicolumn{6}{|c|}{ TG** } \\
\hline & \multicolumn{3}{|c|}{ Güz } & \multicolumn{3}{|c|}{ Bahar } & \multicolumn{3}{|c|}{ Güz } & \multicolumn{3}{|c|}{ Bahar } \\
\hline & $\mathbf{X}$ & SS & $\mathrm{p}^{* * *}$ & $\mathbf{X}$ & SS & $\mathrm{p} * * *$ & $\mathbf{X}$ & SS & $\mathrm{p} * * *$ & $\mathbf{X}$ & SS & $\mathrm{p} * * *$ \\
\hline SDÖ & 2.37 & .37 & .093 & 2.29 & .39 & .200 & 2.62 & .26 & .015 & 2.58 & .27 & .200 \\
\hline
\end{tabular}

*SDÖ: Sosyometrik Derecelendirme Ölçeği, **ÖG: Özel Gereksinimli, TG: Tipik Gelişen, ***Kolmogorov-Smirnov Normallik Testi

Tablo 2 incelendiğinde TG çocukların Güz ve Bahar ölçümlerinde ÖG çocuklardan daha yüksek sosyal puanı elde ettikleri ayrıca ÖG ve TG çocukların her iki ölçümde de sosyal kabul puan ortalamaları arasında küçük değişimler oluştuğu ve her iki grupta da sosyal kabul puanlarında küçük düşüşler ortaya çıktığı görülmektedir. Her iki grubun Güz ve Bahar ölçümlerine ilişkin yapılan normallik analizlerinde elde edilen değerlere göre normal dağılımın sağlanamadığı belirlenmiştir.

\section{ÖG ve TG Çocuk Gruplarının Güz-Bahar Ölçümlerine Göre Sosyal Kabulleri Arasında} Anlamlı Fark Var midır?

ÖG ve TG çocukların Güz ve Bahar ölçümlerinde almış oldukları sosyal kabul puanları iki grup arasında Mann Whitney-U testi ile karşılaştırılmıştır. Elde edilen sonuçlar Tablo 3'te sunulmuştur.

Tablo 3. ÖG ve TG çocukların güz ve bahar ölçüm puanlarının gruplar arası karşılaştırlması

\begin{tabular}{|c|c|c|c|c|c|}
\hline Ölçek* & Gruplar** & $\mathbf{N}$ & S1ra Ort. & Sira Top. & $U$ \\
\hline \multicolumn{6}{|c|}{ Güz } \\
\hline \multirow{2}{*}{ SDÖ } & ÖG & 47 & 38.00 & 1786.00 & \multirow{2}{*}{$658.00^{* * *}$} \\
\hline & TG & 47 & 57.00 & 2679.00 & \\
\hline \multicolumn{6}{|c|}{ Bahar } \\
\hline \multirow{2}{*}{ SDÖ } & ÖG & 47 & 36.97 & 1737.50 & \multirow{2}{*}{$609.50^{* * *}$} \\
\hline & TG & 47 & 58.03 & 2727.50 & \\
\hline
\end{tabular}

*SDÖ: Sosyometrik Derecelendirme Ölçeği, **ÖG: Özel Gereksinimli, TG: Tipik Gelişen, ${ }^{* * *}$ p $<.001$

ÖG ve TG çocukların Güz ve Bahar ölçümlerinde aldıkları puanlar iki grup arasında karşılaştırıldığında anlamlı farklılık olduğu görülmektedir (Bkz. Tablo 3). Çocukların Güz ve Bahar 
ölçümlerinden elde edilen sosyal kabul puan ortalamaları incelendiğinde (Bkz. Tablo 2) TG çocukların ÖG akranlarına göre daha yüksek puanlar aldıkları belirlenmiştir.

ÖG ve TG Çocuk Grupları İçinde Güz-Bahar Ölçümlerine Göre Sosyal Kabulleri Arasında Anlamlı Fark Var midır?

Çalışma grubunda yer alan ÖG ve TG çocukların Güz-Bahar dönemlerinde yapılan değerlendirmelerinde aldıkları puanları her bir grup içinde ayrı ayrı Wilcoxon İşaretli Sıralar testi ile karşılaştırılmışır. Elde edilen sonuçlar Tablo 4’te gösterilmiştir.

Tablo 4. ÖG ve TG çocukların güz ve bahar ölçüm puanlarının grup içi karşılaştırılması

\begin{tabular}{|c|c|c|c|c|c|}
\hline Ölçek* & Ölçümler & $\mathbf{N}$ & Sira Ort. & S1ra Top. & $z$ \\
\hline \multicolumn{6}{|c|}{ ÖG** } \\
\hline \multirow{3}{*}{ SDÖ } & Negatif Sira & 27 & 25.48 & 688.00 & \multirow{3}{*}{-1.925} \\
\hline & Pozitif Sira & 18 & 19.28 & 347.00 & \\
\hline & Eşit & 2 & & & \\
\hline \multicolumn{6}{|c|}{ TG** } \\
\hline \multirow{3}{*}{ SDÖ } & Negatif Sira & 25 & 22.80 & 570.00 & \multirow{3}{*}{-.875} \\
\hline & Pozitif Sira & 19 & 21.11 & 420.00 & \\
\hline & Eşit & 3 & & & \\
\hline
\end{tabular}

Tablo 4 incelendiğinde ÖG çocukların Güz-Bahar ölçüm puanları karşılaştırıldığında sosyal kabul açısından anlamlı farklılık olmadığı görülmektedir, ancak ölçümlerde elde edilen puan ortalamaları incelendiğinde (Bkz. Tablo 2) Bahar ölçümlerinde sosyal kabul düzeylerinde küçük bir düşüş olduğu belirlenmiştir. TG çocukların Güz-Bahar ölçüm puanları Wilcoxon İşaretli Sıralar testi ile karşılaştırıldığında da benzer şekilde sosyal kabul düzeylerinde anlamlı farklılık olmadı̆̆1 görülmektedir. Tablo 2'de yer alan ölçüm sonuçları incelendiğinde TG çocukların sosyal kabul düzeylerinde de Bahar ölçümlerinde sosyal kabul düzeylerinde küçük bir düşüş olduğu belirlenmiştir.

\section{ÖG ve TG Çocuk Grupları Arasında Güz-Bahar Ölçümlerindeki Değişimlere Göre Sosyal} Kabul Düzeyleri Arasında Anlamlı Fark Var mıdır?

Çalışma kapsamında ÖG ve TG çocukların sosyal kabul düzeylerinde Güz-Bahar ölçümleri arasında iki grup için farkların farkı belirlenmiş ve değişimler Mann Whitney-U testi ile karşılaştırılarak sonuçlar Tablo 5’te gösterilmiştir.

Tablo 5. ÖG ve TG çocukların güz-bahar ölçümleri arasındaki değişimlerinin karşılaştırılması

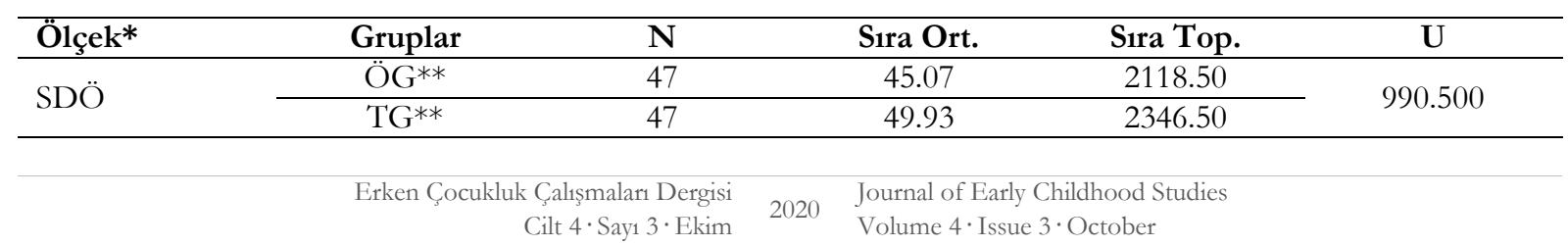


*SDÖ: Sosyometrik Derecelendirme Ölçeği, **ÖG: Özel Gereksinimli, TG: Tipik Gelişen

Tablo 5 incelendiğinde ÖG ve TG çocukların Güz-Bahar ölçümlerinde sosyal kabul düzeyleri arasındaki değişimler karşılaştırıldığında iki grup arasında anlamlı farklılık olmadığı görülmüştür. Her iki grubun yıl içinde sosyal kabul düzeylerinde görülen değişimler arasında anlamlı farklılık tespit edilmemiştir.

\section{SONUÇ ve TARTIŞMA}

$\mathrm{Bu}$ araştırmada ÖG ve TG çocukların sosyal kabul düzeyleri gruplar arasında ve grup içinde boylamsal olarak incelenmiş, ayrıca iki grup için Güz-Bahar ölçümlerinden elde edilen sosyal kabul puanları farkları da karşılaştırılmıştır. Gruplar arası karşılaştırma sonucuna göre, ÖG çocukların TG akranlarına göre öğretim yılı başında ve sonunda yapılan değerlendirmelerde anlamlı düzeyde daha düşük sosyal kabul düzeyi gösterdikleri belirlenmiştir. Bu bulgular daha önce yapılan araştırmaların sonuçları ile benzerlik göstermektedir (Bakkaloğlu ve diğerleri, 2019; Buysse, Goldman ve Skinner, 2002; Ferreira ve diğerleri, 2017; Keane ve Calkins, 2004; Koster, Pijl, Nakken ve Van Houten-van den Bosch, 2010; Mand, 2007; van der Wilt ve diğerleri, 2019).

İki grup için ayrı ayrı öğretim yılının başı ile sonunda yapılan ölçümler karşılaştırıldığında okul öncesi kurumda geçirdikleri bir yıl içinde sosyal kabul düzeyleri açısından her iki grup çocuk için anlamlı bir farklılık oluşmadığı görülmüştür. Bu bulgu ÖG çocukların okul öncesi bütünleştirme uygulamalarından yararlanmalarına ilişkin sorunlar olduğunu, bütünleştirme ortamlarında bu çocukların sosyal kabullerinin artırılması için etkili çalışmaların yapılmadığını ya da yapılan çalışmaların etkili sonuçlarının olmadığını düşündürmüştür. Ayrıca ÖG ve TG çocukların yıl başında ve yıl sonunda yapılan ölçümler arasındaki değişimleri karşılaştırıldığında da değişkenlerde görülen değişim düzeyleri arasında da anlamlı farklılık tespit edilmemiştir. Alanyazında bu konuda yapılan çalışmalarda çocukların sosyal kabul düzeylerinin yalnızca tek bir ölçüm ile belirli bir zamandaki durumlarının tespit edildiği görülmektedir (Küçüker, Işıkoğlu-Erdoğan ve Çürük, 2014; Vuran, 2005). Yapılan bu boylamsal çalışmanın Türkiye'deki okul öncesi bütünleştirme uygulamalarının etkisine ve kalitesine ilişkin fikir verdiği söylenebilir. Bakkaloğlu, Sucuoğlu ve Yılmaz (2019) tarafından yürütülen bir çalışmada okul öncesi bütünleştirme sınıflarının kalitesinin önemli düzeyde yetersiz olduğu ve kalitenin önemli yordayıcılarının öğretmenlerin bütünleştirmeye yönelik görüşleri ve bütünleştirme konusunda eğitim almaları olduğu bulunmuştur. Elde edilen bu bulgular 1şığında bütünleştirme uygulamaları kapsamında yürütülen hizmetlerin kalitesinin geliştirilmesine ve öğretmenlerin mesleki gelişimlerinin desteklenmesine ihtiyaç olduğu söylenebilir. 
Bütünleştirme uygulamalarının beklenilen olumlu çıktıları arasında ÖG çocukların akranları tarafından sosyal kabulünün sağlanması ve TG çocukların bireysel farklılıklara ilişkin bilgilerinin artması da yer almaktadır. Ancak elde edilen bulgular ÖG çocukların TG akranlarına göre zayıf sosyal kabule sahip olduklarını ve bu durumun öğretim yılının sonunda da devam ettiğini göstermektedir. ÖG çocukların sosyal kabul düzeyleri niçin gelişmemiştir? Sosyal kabul bireye yönelik diğerlerinin tutumları olarak tanımlanmaktadır. Tutumlar yargısal eğilimlerdir ve değişmesi zaman alabilmektedir. Bu bağlamda problem davranış gösteren ya da bağlama uygun sosyal becerileri kullanmakta sınırlılıklar gösteren, akranları ile etkileşime girerken iletişimde güçlük yaşayabilen ÖG çocukların akranları tarafindan bu davranışlar ile ilişkilendirilmeleri sonucunda oluşan tutumlar sosyal kabulü etkilemektedir (de Boer, Pijl, Post ve Minnaert, 2013). Nitekim önceki araştırmalar okul öncesi eğitim ortamlarında ÖG olan çocukların TG akranlarına göre daha fazla problem davranış sergilediklerini ifade etmektedir (Bakkaloğlu ve diğerleri, 2019; Keane ve Calkins, 2004). Çocukların birlikte geçirdikleri öğretim yılının sonunda sosyal kabul düzeylerinde bir artış görülmemiş olmasının nedeninin bu durum olabileceği düşünülmektedir.

Yapılan çalışmalarda sosyal kabul ile ilişkili pek çok değişkenin olduğu ifade edilmektedir. Örneğin çocukların akranları ile etkileşime girme tarzları (Meece ve Mize, 2010), sosyal ve duygusal yeterlilikleri (Sette, Spinrad ve Baumgartner, 2013), zihin kuramı becerileri (Slaughter, Imuta, Peterson ve Henry, 2015) akranları tarafindan sosyal kabulleri üzerinde etkili olmaktadır. Benzer şekilde otizm spektrum bozukluğu olan çocuklarda sosyal kabul ile güçlü bir ilişkisi bulunan öğrenci-öğretmen ilişkisi ile ebeveynlik davranışları arasında da ilişki bulunduğu güncel bir çalışmada ortaya konulmuştur (Losh, Tipton, Eisenhower ve Blacher, 2019). Bir diğer değişken ÖG çocukların yetersizliklerinin derecesi olarak kabul edilmekte; ancak bu konuda çelişkili sonuçlar olduğu vurgulanmaktadır (Buysse ve diğ., 2002). Yetersizliğin derecesinin çocukların sosyal becerileri ve dil becerileri ile ilişkili olduğu düşünüldüğ̈nde, bu becerilerdeki yetersizliklerin artması ile akran etkileşimi ve sosyal kabul olumsuz yönde etkilenmektedir (Son ve diğ., 2014). Bu araştırmada ise çalışma grubunun küçük olması nedeniyle, ÖG çocukların sosyal kabullerinin ve sosyal kabuldeki değişimlerin yetersizliğin türüne ve derecesine göre değişip değişmediği incelenememiştir.

Bulgular çalışma grubunda yer alan çocukların bir yıllık okul öncesi eğitim sürecinin sonunda sosyal kabul açısından gelişme olmadığını gösteriyor olsa da durum bu araştırmanın sınırlılıkları ile birlikte değerlendirilmelidir. İlk olarak araştırmanın çalışma grubunda 12 farklı okulda 41 farklı sınıftan toplam 94 çocuk bulunduğu dikkate alınmalıdır. Okul öncesi eğitim kurumlarında ÖG ve NG çocukların etkileşimlerinin niteliğinin değerlendirilebilmesi için daha geniş bir örneklem ile 
çalışılması gereklidir. İkinci olarak bu çalısmada çocukların okul öncesi eğitimden sağlayacakları çıktılara ilişkin tüm değişkenlere (gelişimsel çıktılar gibi) yer verilmemiştir. Benzer şekilde çocuk çıktılarını etkileyebilen, öğretmenlerin bütünleştirme konusundaki bilgi ve tutumları, sınıftaki çocuk sayısı ve çocuk / yetişkin oranı, sınıfın fiziki özellikleri, programın kalitesi gibi özellikler de çalışma kapsamına alınmamıştır. Bu nedenle ileri çalışmalarda, büyük gruplardan toplanacak verilerle, bu Özelliklerin birlikte ele alınmasının, ÖG çocukların sosyal kabulleri konusunda önemli veriler ortaya ç1karabileceği düşünülmektedir.

Göz önünde bulundurulabilecek bir diğer durum ise çocukların sosyal kabul düzeylerinin arkadaşlık ilişkilerini yansıtmamasıdır. Sıklıkla beraber incelenen "sosyal kabul” ve "karşılıklı arkadaşlık" birbirinden ayırılması gereken iki kavramdır (Beazidou ve Botsoglou, 2016). Karşılıklı arkadaşlığın kalıcılığını inceledikleri çalışmalarında Frostad, Mjaavatn ve Pijl (2011), ÖG çocukların karşılıklı arkadaşlıklarının sayısının TG akranlarından daha az olduğunu ifade etmişlerdir. Diğer taraftan, çocukların sınıf içerisinde karşılıklı arkadaş edindikleri durumlarda genel sosyal kabul düzeylerinden bağımsız olarak bütünleştirme uygulamalarından yarar sağlayabilmelerinin mümkün olduğu açıklanmaktadır (Asher ve Weeks, 2018). Bu bağlamda çocukların sosyal kabul düzeylerinin "karşl1ıklı arkadaşlık" durumları ile birlikte ve uygun yöntemler ile incelenmesinin gerekli olarak ortaya çıkmaktadır.

Bütünleştirme uygulamalarının beklenilen olumlu etkiyi sağlaması ve ÖG çocukların akranları tarafından kabullerinin artması için öncelikle öğretmenlerin akran ilişkilerini artıracak sınıf etkinlikler düzenlemeleri önerilmektedir. Bu amaçla öğretmenler sınıfların çocuklar arası etkileşimleri destekleyecek müdahale programlarını hayata geçirmelidirler. Akranlar ile olumlu etkileşimlerin sağlanması için ise ÖG çocukların iletişim ve sosyal becerilerinin desteklenmesi oldukça önemlidir. Diğer taraftan, küçük çocuklar bir kez olumsuz bir durum ile etiketlendikten sonra akranlarının tutumlarının ve ÖG çocuğa karşı algının değişmesi çok güçtür. Bu sebeple okul öncesi eğitim ortamlarına ÖG ve TG tüm çocukların iyi hazırlanmalarının gerektiği düşünülmektedir. Bu bağlamda okul öncesine geçişlerin iyi planlanmasının önemi bir kez daha öne çıkmaktadır (Bakkaloğlu, 2013). Ev ortamından okul öncesi eğitim ortamına iyi, sorunsuz ve yumuşak bir geçiş yapılması çocuğun okula uyumunu arttıracaktır. Bu sayede ÖG çocukların daha az problem davranış sergilemesi ile akranları ve öğretmenleriyle daha olumlu ilişki ve iletişim kurması mümkün olacaktır. Okul öncesi eğitime geçiş, sınıf ortamında sosyal beceri öğretimi, akranlar ile iletişim becerilerinin desteklenmesi için müdahale programlarının hazırlanması ve bu müdahale programlarının etkililiğinin incelenmesinin önemli olduğu düşünülmektedir. Yapılacak 
yeni araştırmalarda ÖG çocukların bütünleştirme uygulamalarından elde ettikleri yararlar daha uzun süreli boylamsal araştırmalarla incelenmelidir.

Sonuç olarak, etkili bütünleştirme uygulamaları için tüm çocukların etkinliklere aktif olarak katılabileceği nitelikli okul öncesi ortamların hazırlanması büyük önem taşımaktadır. Bricker (1995) bütünleştirici ortamların hazırlanması için ÖG çocuklara yönelik olumlu tutumların geliştirilmesi gerektiğini savunurken, Guralnick ise (1999) nitelikli bütünleştirme ortamlan için öğretmenlerin tüm çocuklar arasında bağlllı̆̆ (connectedness) oluşturmaları ve ÖG çocukların sosyal ilişkilerinin kalitesini artırmalarının gereklilik olduğunu vurgulamaktadır. Diğer taraftan okul öncesi eğitimin en önemli elemanı olan gelişime uygun uygulamalar kavramına göre (Fox, Hanline, Vail, \& Galant, 1994) tüm çocuklar birlikte oynamalı ve materyalleri birlikte keşfetmelidirler (Favazza, Roe, Philipsen, Kumar, 2000). Öğretmenler sınıflarında olumlu akran desteği (Smith, Simon ve Bramlett, 2009), iletissim becerilerinin desteklenmesi (Hansen, Blakely, Dolata, Raulston ve Machalicek, 2014) ve sosyal duygusal gelişimin desteklenmesi (McCabe ve Altamura, 2011) uygulamalarına yer verdiklerinde ÖG çocukların sosyal kabullerini desteklemeleri mümkün olacaktır. Ülkemizde de okul öncesi öğretmenlerin sınıflarındaki tüm çocukların etkileşimlerini ve arkadaşlıklarını artıracak ve dolayısıyla ÖG çocukların sosyal kabulünü artıracak önlemler almaları ve etkinlikler planlamaları gereklidir. Ancak okul öncesi öğretmenlerinin ÖG ve NG çocukların etkileşimlerini sağlama ve ÖG çocukları akranlarıyla birlikte etkinliklere dahil etmek için yeterli bilgi ve donanıma sahip olmadıkları görülmektedir (Bakkaloğlu ve diğerleri, 2019; Sucuoğlu, Bakkaloğlu, İşcen-Karasu, Demir ve Akalın 2014). Bu nedenle OÖ öğretmenler için geliştirilen hizmet içi ve hizmet sonrası programlarda sosyal kabul, sosyal etkileşim, tüm çocukların etkileşime katılımı ve sosyal beceri öğretimi konularına yer verilmesinin önemli olduğu düşünülmektedir.

\section{KAYNAKÇA}

Aguiar, C., Moiteiro, A. R., \& Pimentel, J. S. (2010). Classroom quality and social acceptance of preschoolers with disabilities. Infants \& Young Children, 23(1), 34-41.

Andrade, B. F., Waschbusch, D. A., King, S., Thurston, C., McNutt, L., Terrio, B., \& Northern Partners in Action for Children and Youth, Nova Scotia. (2005). Teacher-classified peer social status: Preliminary validation and associations with behavior ratings. Journal of Psychoeducational Assessment, 23(3), 279-290.

Arnold, D. H., Kupersmidt, J. B., Voegler-Lee, M. E., \& Marshall, N. A. (2012). The association between preschool children's social functioning and their emergent academic skills. Early Childhood Research Quarterly, 27(3), 376-386.

Asher, S. R., Singleton, L. C., Tinsley, B. R., \& Hymel, S. (1979). A reliable sociometric measure for preschool children. Developmental Psychology, 15(4), 443-444. 
Asher, S. R., \& Weeks, M. S. (2018). Friendships in childhood. In A. L. Vangelisti \& D. Perlman (Eds.), The Cambridge handbook of personal relationships (2nd ed., pp. 119-134). Cambridge: Cambridge University Press.

Bakkaloğlu, H. (2013). Parental views on the transition process of children with special needs from early intervention to preschool. Education and Science, 38(169), 311-327.

Bakkaloğlu, H., \& Sucuoğlu, B. (2018). School adjustment of children with and without special needs in preschool classrooms. Elementary Education Online, 17(2), 580-595.

Bakkaloğlu, H., Sucuoğlu, B., \& Özbek, A. B. (2019). Examining social acceptance levels of children with special needs and typical development in preschool classrooms. Elementary Education Online, 18(2), 521-538.

Bakkaloğlu, H., Sucuoğlu, B., \& Yilmaz, B. (2019). Quality of inclusive preschool classrooms: predictive variables. Education and Science, 44(199), 223-238.

Balda, S., Punia, S., \& Punia, D. (2002). Peer Rating Scale: A reliable sociometric measure for preschool children. Journal of Psychometry, 15(1), 21-28.

Baydık, B., \& Bakkaloğlu, H. (2009). Predictors of sociometric status for low socioeconomic status elementary mainstreamed students with and without special needs. Educational Sciences: Theory and Practice, 9(2), 435-447.

Beazidou, E., \& Botsoglou, K. (2016). Peer acceptance and friendship in early childhood: The conceptual distinctions between them. Early Child Development and Care, 186(10), 1615-1631.

Birch, S. H., \& Ladd, G. W. (1997). The teacher-child relationship and children's early school adjustment. Journal of School Psychology, 35(1), 61-79.

Booth, T., \& Ainscow, M. (2013). Index for inclusion. Developing learning and participation in schools (3rd ed.). Bristol: CSIE.

Bricker, D. (1995). The challenge of inclusion. Journal of Early Intervention, 19(3), 179-194.

Buhs, E. S., \& Ladd, G. W. (2001). Peer rejection as antecedent of young children's school adjustment: An examination of mediating processes. Developmental Psychology, 37(4), 550.

Buhs, E. S., Ladd, G. W., \& Herald, S. L. (2006). Peer exclusion and victimization: Processes that mediate the relation between peer group rejection and children's classroom engagement and achievement. Journal of Educational Psychology, 98, 1-13.

Buysse, V., Goldman, B. D., \& Skinner, M. L. (2002). Setting effects on friendship formation among young children with and without disabilities. Exceptional Children, 68(4), 503-517.

Cambra, C., \& Silvestre, N. (2003). Students with SEN in the inclusive classroom: Social integration and self-concept. European Journal of Special Needs Education 18(2), 197-208.

Cohen, L., Manion, L., \& Morrison, K. (2007). Surveys, longitudinal, crosssectional and trend studies. In L. Cohen L, L. Manion \& K. Morrison (Eds.), Research methods in education (6th ed., pp. 205-225). London and New York: Routledge, Taylor \& Francis Group. 
de Boer, A., Pijl, S. J., Post, W., \& Minnaert, A. (2013). Peer acceptance and friendships of students with disabilities in general education: The role of child, peer, and classroom variables. Social Development, 22(4), 831-844.

Demir, Ş. (2016). Öğretmen eğitimi programmnn kaynasstrma uygulamalar yürütülen okul öncesi smeflardaki ögretmen ve özel gereksinimli çocuklar üzerindeki etkileri (Doktora tezi). Ankara Üniversitesi, Eğitim Bilimleri Fakültesi, Ankara.

Demirkaya, P. N., \& Bakkaloğlu, H. (2015). Examining the student-teacher relationships of children both with and without special needs in preschool classrooms. Educational Sciences: Theory \& Practice, 15(1), 159-175.

Denham, S. A., \& Holt, R. W. (1993). Preschoolers' likability as cause or consequence of their social behavior. Developmental Psychology, 29(2), 271-275.

Diamond, K. E., Hong, S. Y., \& Tu, H. (2008). Context influences preschool children's decisions to include a peer with a physical disability in play. Exceptionality, 16(3), 141-155.

Dietrich, S. L. (2005). A look at friendships between preschool-aged children with and without disabilities in two inclusive classrooms. Journal of Early Childhood Research, 3(2), 193-215.

Ewing, A. R., \& Taylor, A. R. (2009). The role of child gender and ethnicity in teacher-child relationship quality and children's behavioral adjustment in preschool. Early Childhood Research Quarterly, 24(1), 92-105.

Favazza, P. C., La Roe, J., Phillipsen, L., \& Kumar, P. (2000). Representing young children with disabilities in classroom environments. Young Exceptional Children, 3(3), 2-8.

Ferreira, M., Aguiar, C., Correia, N., Fialho, M., \& Pimentel, J. S. (2017). Social experiences of children with disabilities in inclusive Portuguese preschool settings. Journal of Early Intervention, 39(1), 33-50.

Fox, L., Hanline, M. F., Vail, C. O., \& Galant, K. R. (1994). Developmentally appropriate practice: Applications for young children with disabilities. Journal of Early Intervention, 18(3), 243-257.

Frederickson, N. L., \& Furnham, A. F. (1998). Use of sociometric techniques to assess the social status of mainstreamed children with learning difficulties. Genetic, Social, and General Psychology Monographs, 124(4), 381-433.

Frostad, P., Mjaavatn, P. E., \& Pijl, S. J. (2011). The stability of social relations among adolescents with special educational needs (SEN) in regular schools in Norway. London Review of Education, 9(1), 83-94.

Hamre, B. K., \& Pianta, R. C. (2001). Early teacher-child relationships and the trajectory of children's school outcomes through eighth grade. Child Development, 72(2), 625-638.

Hansen, S. G., Blakely, A. W., Dolata, J. K., Raulston, T., \& Machalicek, W. (2014). Children with autism in the inclusive preschool classroom: A systematic review of single-subject design interventions on social communication skills. Review Journal of Autism and Developmental Disorders, 1(3), 192-206. 
Herndon, K. J., Bailey, C. S., Shewark, E. A., Denham, S. A., \& Bassett, H. H. (2013). Preschoolers' emotion expression and regulation: Relations with school adjustment. The Journal of Genetic Psychology, 174(6), 642-663.

Guralnick, M. J. (1999). The nature and meaning of social integration for young children with mild developmental delays in inclusive settings. Journal of Early Intervention, 22, 70-86.

Guralnick, M. J. (2001). A framework for change in early childhood inclusion. In M. J. Guralnick (Ed.), Early childhood inclusion: Focus on change (pp. 3-35). Baltimore: Brookes.

Jerome, E. M., Hamre, B. K., \& Pianta, R. C. (2009). Teacher-child relationships from kindergarten to sixth grade: Early childhood predictors of teacher-perceived conflict and closeness. Social Development, 18(4), 915-945.

Johnson, C., Ironsmith, M., Snow, C. W., \& Poteat, G. M. (2000). Peer acceptance and social adjustment in preschool and kindergarten. Early Childhood Education Journal, 27(4), 207-212.

Justice, L. M., Petscher, Y., Schatschneider, C., \& Mashburn, A. (2011). Peer effects in preschool classrooms: Is children's language growth associated with their classmates' skills?. Child Development, 82(6), 1768-1777.

Kapc1, E. G., \& Çorbacı-Oruç, A. (2003). Okul-öncesi çocuklarda sosyometrik yöntemlerin karşılaştırılması. Cocuk ve Gençlik Ruh Sağhlğ Dergisi, 10(3), 100-107.

Keane, S. P., \& Calkins, S. D. (2004). Predicting kindergarten peer social status from toddler and preschool problem behavior. Journal of Abnormal Child Psychology, 32, 409-423.

Kingery, J. N., Erdley, C. A., \& Marshall, K. C. (2011). Peer acceptance and friendship as predictors of early adolescents' adjustment across the middle school transition. Merrill-Palmer Quarterly, 57(3), 215-243.

Koster, M., Pijl, S. J., Nakken, H., Van Houten, E., \& Van Houten-van den Bosch, E. J. (2010). Social participation of students with special needs in regular primary education in the netherlands. International Journal of Disability Development and Education, 57(1), 59-75.

Küçüker, S., Iş1koğlu-Erdoğan, N., \& Çürük, Ç. (2014). Peer acceptance of children with disabilities in inclusive kindergarten classrooms. Pamukkale University Journal of Education, 36(June 2014/II), 163-177.

Ladd, G. W., Birch, S. H., \& Buhs, E. S. (1999). Children's social and scholastic lives in kindergarten: Related spheres of influence?. Child Development, 70(6), 1373-1400.

Ladd, G. W., Kochenderfer, B. J., \& Coleman, C. C. (1996). Friendship quality as a predictor of young children's early school adjustment. Child Development, 67, 1103-1118.

Ladd, G. W., Kochenderfer, B. J., \& Coleman, C. C. (1997). Classroom peer acceptance, friendship, and victimization: Destinct relation systems that contribute uniquely to children's school adjustment?. Child Development, 68(6), 1181-1197.

Lewis, R. B., \& Doorlag, D. H. (1999). Teaching special students in general education classrooms. New Jersey, NJ: Prentice Hall. 
Losh, A., Tipton, L. A., Eisenhower, A., \& Blacher, J. (2019). Parenting behaviors as predictive of early student-teacher relationships in ASD. Journal of Autism and Developmental Disorders, 49(9), 3582-3591.

Mand, J. (2007). Social position of special needs pupils in the classroom: A comparison between German special schools for pupils with learning difficulties and integrated primary school classes. European Journal of Special Needs Education, 22(1), 6-14.

McCabe, P. C., \& Altamura, M. (2011). Empirically valid strategies to improve social and emotional competence of preschool children. Psychology in the Schools, 48(5), 513-540.

McDermott, P. A. (1993). National standardization of uniform multisituational measures of child and adolescent behavior pathology. Psychological Assessment, 5(4), 413-424.

Meece, D., \& Mize, J. (2010). Multiple aspects of preschool children's social cognition: Relations with peer acceptance and peer interaction style. Early Child Development and Care, 180(5), 585-604.

Montroy, J. J., Bowles, R. P., Skibbe, L. E., \& Foster, T. D. (2014). Social skills and problem behaviors as mediators of the relationship between behavioral self-regulation and academic achievement. Early Childhood Research Quarterly, 29(3), 298-309.

Nakamichi, K., Nakamichi, N., \& Nakazawa, J. (2019). Preschool social-emotional competencies: Predict school adjustment in Grade 1. Early Child Development and Care, doi: 10.1080/03004430.2019.1608978

Odom, S. L., Vitztum, J., Wolery, R., Lieber, J., Sandall, S., Hanson, M. J., ... Horn, E. (2004). Preschool inclusion in the United States: A review of research from an ecological systems perspective. Journal of Research in Special Educational Needs, 4(1), 17-49.

Odom, S. L., Zercher, C., Li, S., Marquart, J. M., Sandall, S., \& Brown, W. H. (2006). Social acceptance and rejection of preschool children with disabilities: A mixed-method analysis. Journal of Educational Psychology, 98(4), 807-823.

O'Neil, R., Welsh, M., Parke, R. D., Wang, S., \& Strand, C. (1997). A longitudinal assessment of the academic correlates of early peer acceptance and rejection. Journal of Clinical Child Psychology, 26(3), 290-303.

Palermo, F., Hanish, L. D., Martin, C. L., Fabes, R. A., \& Reiser, M. (2007). Preschoolers' academic readiness: What role does the teacher-child relationship play?. Early Childhood Research Quarterly, 22(4), 407-422.

Parker, J. G., \& Asher, S. R. (1987). Peer relations and later personal adjustment: Are low-accepted children at risk? Psychological Bulletin, 102, 357-389.

Prinstein, M. J., \& Giletta, M. (2016). Peer relations and developmental psychopathology. In D. Cicchetti (Ed.), Developmental psychopathology (3rd Ed., Vol. 1, pp. 527-579). Hoboken, NJ: Wiley.

Prino, L. E., Pasta, T., Gastaldi, F. G. M., \& Longobardi, C. (2016). The effect of autism spectrum disorders, Down syndrome, specific learning disorders and hyperactivity and attention 
deficits on the student-teacher relationship. Electronic Journal of Research in Educational Psychology, 14(1), 89-106.

Reed-Victor, E. (2004). Individual differences and early school adjustment: Teacher appraisals of young children with special needs. Early Child Development and Care, 174(1), 59-79.

Roorda, D. L., Verschueren, K., Vancraeyveldt, C., Van Craeyevelt, S., \& Colpin, H. (2014). Teacher-child relationships and behavioral adjustment: Transactional links for preschool boys at risk. Journal of School Psychology, 52(5), 495-510.

Rudasill, K. M. (2011). Child temperament, teacher-child interactions, and teacher-child relationships: A longitudinal investigation from first to third grade. Early Childhood Research Quarterly, 26(2), 147-156.

Rudasill, K. M., Niehaus, K., Buhs, E., \& White, J. M. (2013). Temperament in early childhood and peer interactions in third grade: The role of teacher-child relationships in early elementary grades. Journal of School Psychology, 51(6), 701-716.

Sette, S., Spinrad, T. L., \& Baumgartner, E. (2013). Links among Italian preschoolers' socioemotional competence, teacher-child relationship quality, and peer acceptance. Early Education \& Development, 24(6), 851-864.

Silver, R. B., Measelle, J. R., Armstrong, J. M., \& Essex, M. J. (2005). Trajectories of classroom externalizing behavior: Contributions of child characteristics, family characteristics, and the teacher-child relationship during the school transition. Journal of School Psychology, 43(1), 3960.

Slaughter, V., Imuta, K., Peterson, C. C., \& Henry, J. D. (2015). Meta-analysis of theory of mind and peer popularity in the preschool and early school years. Child development, 86(4), 11591174.

Smith, S. M., Simon, J., \& Bramlett, R. K. (2009). Effects of positive peer reporting (PPR) on social acceptance and negative behaviors among peer-rejected preschool children. Journal of Applied School Psychology, 25(4), 323-341.

Son, E., Peterson, N. A., Pottick, K. J., Zippay, A., Parish, S. L \& Lohrman, S. (2014). Victimization among young children with disabilities: Early risk and protective factors. Exceptional Children, 80, 370-386.

Stone, L. L., Giletta, M., Brendgen, M., Otten, R., Engels, R. C., \& Janssens, J. M. (2013). Friendship similarities in internalizing problems in early childhood. Early Childhood Research Quarterly, $28(2), 210-217$.

Sucuoğlu, B., Bakkaloğlu, H., İşcen-Karasu, F., Demir, S., \& Akalın, S. (2014). Preschool teachers' knowledge levels about inclusion. Educational Sciences: Theory and Practice, 14(4), 1477-1483.

Tur-Kaspa, H., Margalit, M., \& Most, T. (1999). Reciprocal friendship, reciprocal rejection and socio-emotional adjustment: the social experiences of children with learning disorders over a one-year period. European Journal of Special Needs Education, 14(1), 37-48. 
Vaughn, S., Elbaum, B. E., \& Schumm, J. S. (1996). The effects of inclusion on the social functioning of students with learning disabilities. Journal of Learning Disabilities 29(6), 598608.

van der Wilt, F., van der Veen, C., van Kruistum, C., \& van Oers, B. (2019). Why do children become rejected by their peers? A review of studies into the relationship between oral communicative competence and sociometric status in childhood. Educational Psychology Review, 31, 699-724.

Vuran, S. (2005). The sociometric status of students with disabilities in elementary level integration classes in Turkey. Eurasian Journal of Educational Research, 18, 217-235.

Yu, S., Ostrosky, M. M., \& Fowler, S. A. (2015). The relationship between preschoolers' attitudes and play behaviors toward classmates with disabilities. Topics in Early Childhood Special Education, 35(1), 40-51. 